\title{
ÁGUA COMO DIREITO HUMANO: ESTUDO COMPARADO DE SUA PROTEÇÃO NAS ESFERAS JUDICIAIS INTERAMERICANA E EUROPEIA
}

\author{
WATER AS A HUMAN RIGHT: COMPARATIVE STUDY OF ITS PROTECTION IN THE \\ INTER-AMERICAN AND EUROPEAN JURISPRUDENTIAL SPHERES
}

\author{
Paula Strakos*
}

\begin{abstract}
RESUMO
O manejo de água de forma a garantir a prioridade de seu uso para as necessidades básicas biológicas humanas às presentes e futuras gerações é um tema de interesse global e nacional, cuja urgência tem crescido no território brasileiro. Visando tal interesse, o direito humano à água vem ganhado força política internacional nas últimas décadas e assim também vem gradativamente se consolidando na arena jurídica. $\mathrm{O}$ artigo analisa a conjuntura do direito à água no direito internacional, passando então à análise de sua implementação nos sistemas de proteção de direitos humanos interamericano e europeu, em especial quanto à jurisprudência disponível, a fim de fazer uma comparação entre esses, bem como entender a aplicabilidade, eficácia e obrigações estatais decorrentes do direito. Conclui-se que o reconhecimento do direito humano à água funciona como importante instrumento para proteção de direitos imediatos individuais, bem como de direitos mediatos difusos, diante da atual ordem político-econômica global.
\end{abstract}

\section{PALAVRAS-CHAVE}

Direitos humanos. Água. Sistemas regionais de proteção de direitos humanos. Estudo comparado. Obrigação estatal.

\begin{abstract}
The management of water resources - so that priority is given to its use to fulfill the human basic biological needs for present and future generations - is a topic of international and national concern, having just lately increased in importance in Brazil. In response to the concerns of the international community, a human right to water has gained force in international politics in the last decades and has been gradually incorporated into the legal arena. This article analyses the stand of the right to water in international law and, considering especially the available case law, builds up a comparative study of its implementation in the Inter-American and European systems for the protection of human rights, with the aim to identify its applicability, effectiveness, and the corresponding State's obligations. It concludes that the recognition of the human right to water can work as an important instrument to protect direct individual rights, as well as indirect collective rights, in face of the current political and economic global order.
\end{abstract}

\section{KEYWORDS}

Human rights. Water. Regional systems for the protection of human rights. Comparative study. State's obligation.

\footnotetext{
* Doutoranda em Direito pela Freie Universität Berlin (Universidade Livre de Berlim - Alemanha). Bolsista Capes do Programa de Doutorado Pleno na Alemanha. Mestra em Direito Internacional e Europeu pela mesma universidade. Graduada em Direito pela Universidade Presbiteriana Mackenzie. Advogada. E-mail: paula_strakos@hotmail.com
} 


\section{INTRODUÇÃO}

O elemento água é essencial para a vida biológica humana, bem como para a manutenção dos processos que permitem a organização humana como agricultura, indústria e meio ambiente equilibrado. Seu consumo vem crescendo de forma exponencial nas últimas décadas e está previsto que suba 55\% até 2050 (LEFLAIVE, 2012, p. 208). Tal porcentagem está muito acima do crescimento populacional, ao qual inicialmente se atribuía a principal causa de uma "crise hídrica global”, e se deve ao fato de o crescimento econômico também exigir o aumento dos usos de água, passando por geração de energia, extração de minério, processos industriais múltiplos, produção agropecuária e até a refrigeração de bases de dados eletrônicos.

O tema água - e a necessidade de seu manejo de forma sustentável com vistas a garantir o seu uso para as necessidades básicas do ser humano - já ocupa a agenda política internacional desde os anos de 1970, ao lado do surgimento da consciência das limitações do meio ambiente enquanto fonte finita de recursos e do direito ambiental em si. Os debates sobre o tema levaram ao conhecimento de que existe um fator social fortemente associado à disponibilidade de água. Nesse sentido, as Nações Unidas reconhecerem que a “crise hídrica” mundial está muito mais relacionada às questões de poder, desigualdade social e pobreza do que com uma questão de disponibilidade do recurso $^{1}$. Entre as principais estratégias para resolver o problema está a luta pela garantia do acesso à água e saneamento básico como direitos humanos, de forma a garantir a prioridade do uso do recurso água para a satisfação das necessidades básicas das presentes e futuras gerações²

O manejo sustentável de recursos hídricos também é um tema de interesse global, já que os fluxos de água e os processos humanos que dela necessitam não conhecem limites territoriais. Contudo, o tema vem gradativamente ganhando importância em âmbito nacional. Fatos recentes têm mostrado que, apesar de o Brasil ser detentor de uma das maiores reservas hídricas do mundo (ANA, 2013, p. 45), escapa-lhe a oportunidade de gerir o recurso de forma sustentável. Especula-se que também nesse caso é justamente a abundância de recursos naturais que deixa de gerar incentivos para o seu manejo consciente e sustentável. Assim, ao mito de que a abençoada terra brasileira tem recursos naturais inesgotáveis soma-se outro: de que o crescimento econômico é o principal catalisador do desenvolvimento e que, ao tê-lo por fim, justificam-se os meios de degradação

\footnotetext{
${ }^{1}$ O Relatório de Desenvolvimento das Nações Unidas, 2006, p. V, já relatava: “The scarcity at the heart of the global water crisis is rooted in power, poverty and inequality, not in physical availability." (UNITED NATIONS DEVELOPMENT PROGRAMME, 2006, p. 2) Tradução livre: "A escassez no âmago da crise hídrica global tem suas raízes no poder, pobreza e desigualdade, e não na disponibilidade física do recurso.”

${ }^{2}$ Para os fins do presente artigo, entende-se por "direito humano à água” os direitos de acesso à água e saneamento básico, conforme estabelecidos na Resolução 70/169 (2015) da Assembleia Geral das Nações Unidas.
}

Revista da Faculdade de Direito - UFPR, Curitiba, vol. 61, n. 3, set./dez. 2016, p. 141 - 164 
ambiental, mesmo que tornem o próprio crescimento econômico insustentável.

O Estado brasileiro tem sido sistematicamente ineficaz em resolver o problema de distribuição de água em seu território, começando pela já tradicional seca no semiárido nordestino, passando pela crise hídrica no Sudeste e chegando ao descaso com estudos de impacto ambiental para outorga de licença de uso de água em hipóteses de extremo risco para manutenção do ciclo hídrico, sobretudo nas atividades mineradoras e hidroelétricas. Muito embora o Brasil venha envidando múltiplos esforços para o desenvolvimento econômico, adotando políticas públicas nesse sentido (por exemplo, o Programa de Aceleração do Crescimento) e estando constantemente na iminência de alcançar o nível de desenvolvimento econômico almejado, é preciso lembrar que os recursos naturais de nossas terras também são finitos e que o discurso desenvolvimentista, que prescreve as responsabilidades por encontrar os meios de atrelar o conceito de desenvolvimento ao de sustentabilidade, principalmente aos países desenvolvidos, vai perdendo sentindo diante do cenário hídrico brasileiro.

O reconhecimento do direito à água como sendo fundamental ao homem, pelo direito internacional, serve tanto de ferramenta quanto de alerta para a necessidade de se definirem prioridades e limites para o manejo do recurso, bem como para, quiçá, proteger direitos básicos de grupos minoritários da atuação de seu próprio Estado. Cresce o reconhecimento de que o sistema de governança internacional, baseado no conceito de Estado-nação soberano, possui, em muitos casos, eficácia insuficiente, especialmente no reconhecimento e respeito aos interesses coletivos difusos e, ainda, daqueles de titularidade dos menos privilegiados (MARTIN et al., 2015, p. 1). Dessa forma, fortificam-se também as iniciativas para proteção de direitos individuais na esfera internacional (KUNIG, 2007, p. 187-199).

O presente artigo visa, diante do cenário acima exposto, esmiuçar a proteção jurídica conferida à água enquanto direito humano no âmbito internacional para em seguida fazer um estudo comparativo dos mecanismos de proteção do direito em âmbito regional interamericano e europeu. As cortes regionais desempenham um papel importante na proteção de direitos humanos e na coerção exercida sobre os Estados para que respeitem as normas internacionais. Na falta de mecanismos mais eficientes, resta nessas cortes a esperança de que sejam ouvidos os grupos ou indivíduos (até mesmo de interesses coletivos difusos) cujos interesses são ignorados pelo Executivo e Judiciário de seu próprio país, bem como de que sejam atendidas as demandas de uma nova ordem global (de rápida globalização econômica e lenta regulamentação supranacional).

O relativamente novo direito humano à água é especialmente interessante enquanto objeto de discussão, pois é um direito que exige do Estado tanto medidas de proteção imediata do indivíduo 
ou comunidades, bem como medidas de proteção mediata de interesses difusos, como o meio ambiente equilibrado que permita que o ciclo da água cumpra seu papel de limpar (ou reciclar) o recurso (LEWIS, 2016, p. 39-50).

É importante ressaltar que a presente análise se refere ao sistema europeu de direitos humanos e não engloba uma análise da legislação ou jurisprudência na União Europeia, já que a última está baseada num sistema supranacional, com mecanismos legislativos e de implementação substancialmente diferentes do sistema interamericano. Os sistemas ora comparados apresentam duas diferenças contextuais que valem ser mencionadas. Primeiro, apesar de terem objetivos análogos e colaborarem entre si para unificação da jurisprudência, a Corte Europeia de Direitos Humanos (Corte EDH) e a Corte Interamericana de Direito Humanos (Corte IDH) também apresentam assimetrias institucionais e processuais (MAZZUOLI, 2010, p. 53-56), as quais não serão aprofundadas ao longo deste artigo.

Segundo, faz-se importante contextualizar o tema geopoliticamente. A Organização dos Estados Americanos (OEA) é composta por um número substancial de Estados do eixo Sul, ou países em desenvolvimento, que se posicionam, desde o início do desenvolvimento do direito ambiental internacional e do conceito de desenvolvimento sustentável, como detentores de uma responsabilidade diferenciada (para menos) pelo meio ambiente, conforme consagrado pelo “princípio da responsabilidade comum, mas diferenciada”.

Em regra, tais países também apresentam índices mais baixos no cumprimento de direitos humanos e costumam ter as estruturas do Estado de Direito mais frágeis, de modo que o pleito de minorias tem vias de reclamação menos eficientes. Além disso, integram o sistema os Estados Unidos da América (EUA), Estado desenvolvido economicamente, mas que não pode ser considerado entre os Estados mais entusiastas na defesa de direitos ambientais, em especial quanto ao manejo sustentável de recursos hídricos.

Em face às peculiaridades dos sistemas jurídicos ora apresentados, o presente artigo discutirá o reconhecimento de um direito humano à água nos sistemas normativos internacional, interamericano e europeu, bem como o alcance de sua proteção nas esferas judiciais regionais. Considerando que "as normas de direitos fundamentais são de suma importância como elementos de interpretação e integração do ordenamento jurídico” (VIEIRA JR., 2015, p. 73), o presente estudo objetiva, por meio da identificação e aprofundamento das obrigações estatais dele decorrentes, corroborar o hodierno direito humano à água, de acordo com as normas e jurisprudência internacionais, e, assim, também contribuir para maior clareza na implementação e fortalecimento das políticas públicas nacionais relacionadas com a proteção e controle dos recursos hídricos. 
A pesquisa tem caráter dogmático-analítico com referencial teórico sistemático nas ordens jurídicas internacional, regional interamericana e regional europeia. Em um primeiro momento, visa investigar a temática da proteção de um direito humano à água no conjunto normativo internacional, para, em um segundo momento, proceder à análise nos conjuntos normativo-judiciais regionais interamericano e europeu. Em um terceiro momento será aplicado o método instrumental comparativo para identificar as semelhanças e diferenças entre a implementação do direito humano à água no sistema normativo e judicial interamericano e europeu. Com relação ao método de pesquisa, trata-se de pesquisa qualitativa de caráter documental e bibliográfico, comportando análise não apenas doutrinária, mas principalmente de atos normativos (tanto hard law quanto soft law) e jurisprudência das cortes de direitos humanos regionais relativa ao tratamento da água como direito humano.

\section{PROTEÇÃO DO DIREITO HUMANO À ÁGUA NO ÂMBITO GLOBAL}

Em âmbito internacional, a temática do direito humano à água passou a ser discutida a partir da Conferência de Mar del Plata, em 1977, pela qual o recurso natural água foi reconhecido como bem público ao qual todo indivíduo tem direito em quantidade e qualidade adequadas para o atendimento de suas necessidades básicas, independentemente do estágio de desenvolvimento social e econômico (NAÇÕES UNIDAS, 1977, p. 68).

Desde então foram desenvolvidas diversas tentativas de alcançar o acesso universal à água e ao saneamento básico, inclusive a aferição de um valor econômico ao recurso e a inclusão da iniciativa privada conforme a onda de privatizações dos anos de 1990, que também se mostraram ineficientes ${ }^{3}$. Hoje, rege o consenso político quanto à necessidade da proteção do acesso à água como direito humano, já que é condicionante dos direitos à vida, à dignidade humana, à saúde e a um nível de vida suficiente.

Sobre a perspectiva positiva, apesar de um direito humano à água não estar expressamente previsto na Declaração Universal dos Direitos Humanos (DUDH), no Pacto Internacional sobre Direitos Econômicos, Sociais e Culturais de 19.12.1966 (PIDESC) ou no Pacto Internacional sobre Direitos Culturais e Políticos de 16.12.1966 (PIDCP), o Comitê das Nações Unidas para os Direitos

\footnotetext{
${ }^{3}$ São famosos os casos de privatização das companhias de água e saneamento básico que resultaram em preços inacessíveis para grande parte da população em diversos lugares do mundo, incluindo os casos de Cochabamba, Bolívia, e Buenos Aires, Argentina. Adicionalmente, cf. BLUEMEL, 2004; NICKSON; VARGAS, 2002; FARIA; FARIA; MOREIRA, 2005; LASKOWSKI, 2010, p. 51-60.
} 
Econômicos, Sociais e Culturais (CNUDESC) ${ }^{4}$, órgão responsável pela interpretação e implementação do PIDESC, reconheceu expressamente, por meio do Comentário Geral n. 15 de 2002 (CG15), que o direito humano à água e ao saneamento básico é parte integrante do direito à condição de vida suficiente previsto no art.11(1), § 1 do PIDESC $^{5}$, já que este traz apenas um rol exemplificativo de seus elementos integrantes.

Além disso, reconheceu-se o direito à água e ao saneamento básico como intrinsecamente relacionado ao direito de mais alto nível de saúde possível (art. 12(1), § 1 PIDESC) e aos direitos à moradia e à alimentação adequadas (art. 11(1), § 1 PIDESC). Ainda, segundo as mesmas fontes, o direito humano à água deve ser considerado em conjunto com os direitos humanos previstos na Declaração Internacional de Direitos Humanos, em especial os direitos à vida e à dignidade humana. O direito humano à água é, portanto, um exemplo clássico do funcionamento almejado pela Teoria dos Direitos Fundamentais de Alexy, pela qual o sistema de direitos fundamentais deve estar aberto e receptivo a novos direitos fundamentais, contanto que embasados em direitos já existentes (ALEXY, 2008, p. 69-76).

Os Comentários Gerais do CNUDESC não constituem, em si, direito vinculante nos termos do art. 38 do Estatuto da Corte Internacional de Justiça (ECIJ), mas tem caráter de soft law e gozam de elevada autoridade devido à ampla experiência dos membros do CNUDESC com os temas tratados (LOHSE, 2005, p. 65). São essenciais para o desenvolvimento e fixação das obrigações decorrentes de um determinado direito e são, dessa forma, utilizados por cortes e pelo órgão de decisão como auxiliares na interpretação da norma existente (RUDOLF, 2007, p. 23; WINKLER, p. 38).

Paralelamente, o direito humano à água foi recepcionado, desde a Conferência em Mar del Plata (1977), em diversos documentos na esfera política e jurídica internacional, culminando em seu reconhecimento, de forma unânime e sem ressalvas, pela Assembleia Geral das Nações Unidas, em 17 de dezembro de 2015, por meio da Resolução 70/169 (Resolução 70/169 AGNU). Tal Resolução representa um importantíssimo passo no reconhecimento do direito humano à água, uma vez que seu conteúdo normativo foi pela primeira vez aprovado de forma expressa, unânime e sem ressalvas pelos Estados-membros das Nações Unidas.

Insta salientar que até então o direito humano à água e o direito humano ao saneamento básico eram majoritariamente tratados como um direito único. No entanto, diante da pressão política e social (HELLER, 2015, p. 3) por maior atenção aos aspectos relacionados ao saneamento básico, a

\footnotetext{
${ }^{4}$ O CNUDESC é o órgão instituído pelo Conselho Econômico e Social (ECOSOC) para realizar a interpretação legal, controle e aplicação do PIDESC, nos termos do art. 16 do PIDESC (Pacto 1).

${ }^{5} \mathrm{O}$ CNUDESC também já havia reconhecido o acesso à água como parte integrante do direito à condição de vida suficiente, por meio do Comentário Geral n. 6, de 1995.
} 
Resolução 70/169 reconheceu dois direitos conectados, mas distintos, ambos parte integrante do direito à condição de vida suficiente previsto no art. 11(1), § 1, do PIDESC.

Apesar de a inserção do direito humano à água ser cada vez mais recorrente em documentos internacionais e em ordenamentos jurídicos nacionais, ainda é controverso seu reconhecimento como direito costumeiro vinculante, em razão da dificuldade de comprovação dos elementos constitutivos da prática estatal unificada e sua correspondente opinio juris (DUPUY, 2007, p. 450-463; HOHENWARTER, 2014, p. 93-98; WINKLER, 2012, p. 65-70). De forma vinculante para os Estados signatários, o direito à água é implicitamente reconhecido no PIDESC e expressamente reconhecido em convenções que abrangem grupos ou situações determinados (ratione personae), tais como na Convenção Sobre a Eliminação de Todas as Formas de Discriminação Contra a Mulher (CEDAW), art. 14 § 2(h) $)^{6}$, na Convenção para os Direitos das Crianças (CRC), Parte I, art. 24 § 2(c) ${ }^{7}$ e na Convenção sobre os Direitos de Pessoas com Deficiência (CRPD), art. 28 § 2(a) ${ }^{8}$.

Vale ainda ressaltar que a comunidade internacional e os Estados-membros renovaram recentemente seu compromisso político quanto ao desenvolvimento sustentável, por meio das Metas de Desenvolvimento Sustentável. O tema água foi tratado em um objetivo próprio (n. 6), tendo por principal propósito alcançar, até 2030, o acesso universal à água e ao saneamento básico ${ }^{9}$.

A definição mais atual do direito humano à água está prevista na Resolução 70/169 AGNU, segundo a qual todo indivíduo está intitulado, sem discriminação, à água suficiente, segura, aceitável, física e financeiramente acessível, para uso pessoal e doméstico. O direito humano ao saneamento básico prevê a todo indivíduo, sem discriminação, saneamento básico física e financeiramente acessível em todas as esferas de vida, ou seja, que seja seguro, higiênico, protegido, social e culturalmente aceitável e que permita privacidade e garanta dignidade ${ }^{10}$.

\footnotetext{
${ }^{6}$ CEDAW, 1979, art. 14 § 2(h): “Os Estados-partes adotarão todas as medidas apropriadas para eliminar a discriminação contra mulheres nas zonas rurais, a fim de assegurar, em condições de igualdade entre homens e mulheres, [...] assegurarlhes-ão o direito a: [...] (h) gozar de condições de vida adequadas, particularmente nas esferas da habitação, dos serviços sanitários, da eletricidade e do abastecimento de água, do transporte e das comunicações.”

${ }^{7}$ CRC, 1989, Parte I, art. 24 § 2(c): "Os Estados Partes garantirão a plena aplicação desse direito e, em especial, adotarão as medidas apropriadas com vistas a: [...] (c) combater as doenças e a destruição dentro do contexto dos cuidados básicos de saúde mediante, inter alia, a aplicação de tecnologia disponível e o fornecimento de alimentos nutritivos e de água potável, tendo em vista os perigos e riscos da poluição ambiental;”

${ }^{8}$ CRPD, 2006, art. 28 § 2(a): “[...] sem discriminação baseada na deficiência, e tomarão as medidas apropriadas para salvaguardar e promover a realização desse direito, tais como: (a) assegurar igual acesso de pessoas com deficiência a serviços de água limpa e assegurar o acesso adequado, inclusive acesso financeiro, aos serviços, dispositivos e outros atendimentos apropriados para as necessidades relacionadas com a deficiência;”

${ }^{9}$ Todavia não foi inserido projeto em contexto nacional visando ao atingimento dessa meta.

${ }^{10}$ Resolução 70/169 AGNU, 2015, § 2, no original: "Recognizes that the human right to safe drinking water entitles everyone, without discrimination, to have access to sufficient, safe, acceptable, physically accessible and affordable water for personal and domestic use, and that the human right to sanitation entitles everyone, without discrimination, to have physical and affordable access to sanitation, in all spheres of life, that is safe, hygienic, secure, socially and culturally
} 
O direito à água envolve, ainda, tanto direitos negativos de defesa de liberdade quanto direitos positivos de acesso à prestação de serviços pelo Estado. A defesa de liberdade refere-se ao direito de cada indivíduo de manter o acesso a fontes de água potável ou estruturas de abastecimento de água já existentes, inclusive o contínuo acesso a tal abastecimento, bem como à proteção contra interrupções de fornecimento arbitrárias ou poluição dos recursos hídricos. O direito positivo, por sua vez, é o de cada indivíduo ter acesso a estruturas de água e saneamento básico fornecidas pelo Estado, que tem a obrigação de provê-las de forma acessível e equitativa (CG15, art. 10).

É de se destacar, nesse sentido, que todo direito gera obrigações correspondentes. As obrigações estatais decorrentes do direito humano à água são, assim como todas as obrigações decorrentes de direitos humanos, divididas de forma tríplice em: obrigação de observar, obrigação de proteger e obrigação de cumprir. No CG15 foi dedicado um capítulo inteiro para minuciar o conteúdo de tais obrigações para efetivo cumprimento do direito humano à água (cap. III, arts. 17-38). A obrigação de observar exige que o Estado se abstenha de intervir de forma direta ou indireta no gozo do direito pelo cidadão. A obrigação de proteger requer que o Estado impeça que terceiros indivíduos, grupos, corporações e outras entidades - intervenham no gozo do direito, estando obrigado inclusive à adoção de medidas legislativas, administrativas e outras que impeçam o uso não equitativo ou a poluição das fontes do recurso. Tal obrigação se torna especialmente relevante para os casos que vêm sendo denunciados pela sociedade civil quanto à depleção dos recursos hídricos e à dificuldade de acesso à água potável envolvidas com as atividades de empresas transnacionais nos setores de mineração (GANDRA, 2014). Por fim, a obrigação de cumprir, subdividida em obrigação de facilitar, de promover e de fornecer o acesso à água e ao saneamento básico à população, trata-se de obrigação positiva, pela qual o Estado deve implementar as medidas necessárias para que os indivíduos e comunidades possam usufruir do direito (para uma análise mais detalhada veja WINKLER, 2012, p. 107-125; HOHENWARTER, 2014, p. 114-122).

É importante, também, ressaltar o conceito de “adequabilidade”, necessário para garantia do direito à água pelo Estado, previsto nos arts. 11 e 12 do CG15. Os elementos do direito devem ser adequados à vida e à dignidade humana, bem como para a manutenção da saúde. O conceito de adequabilidade engloba a necessidade de sustentabilidade das práticas do Estado para garantir o direito para as gerações presentes e futuras, nos termos estabelecidos na Agenda 21. O conceito deve

acceptable and that provides privacy and ensures dignity.” Tradução livre: "Reconhece que o direito humano à água intitula todo indivíduo, sem discriminação, à água suficiente, aceitável, física e financeiramente acessível para uso pessoal e doméstico, e que o direito humano ao saneamento básico intitula todo indivíduo, sem descriminação, a ter saneamento básico, física e financeiramente acessível em todas as esferas da vida, que seja seguro, higiênico, protegido, social e culturalmente aceitável e que permita privacidade e garanta dignidade.” 
ser interpretado de forma ampla, levando em conta seu valor como bem cultural, não estando restrito a seu valor econômico. São partes integrantes do conceito da adequabilidade três fatores: disponibilidade, qualidade e acessibilidade. A disponibilidade deve ser contínua e suficiente para os usos pessoais e domésticos (incluindo preparo de alimentos, higiene do corpo, roupas e casa). Quanto à qualidade, vale destacar que deve ser adequada à saúde, ou seja, não deve conter micro-organismos nem substâncias químicas e tóxicas, bem como seu odor, cor e gosto devem ser aceitáveis ${ }^{11}$. A acessibilidade deve ser física, financeira, não discriminatória (tanto formalmente quanto na prática), bem como deve-se garantir o acesso à informação quanto ao fornecimento, qualidade e quaisquer questões relacionadas à água (CG15, 2002, art. 12; WINKLER, 2012, p. 126-139; HOHENWARTER, 2014, p. 106-110).

Por acessibilidade financeira entende-se que o preço da água deve estar ao alcance de todas as camadas da população, de forma a não impedir a realização e fruição de outros direitos. A quantificação da acessibilidade financeira é complexa, pois deve levar em consideração o rendimento familiar e as quantias necessárias para outros direitos fundamentais como alimentação e moradia. Rege o consenso de que o preço pago para realização do direito humano à água deve variar entre três e cinco por cento do orçamento doméstico (UNITED NATIONS DEVELOPMENT PROGRAM, 2006, p. 97; WINKLER, 2012, p. 137).

Além disso, o CG15 incorpora o Princípio da Não Discriminação e o Princípio da Igualdade, previstos respectivamente nos art. $2 \S 2$ e art. 3 do PIDESC, ao ressaltar a importância de se atender especialmente à necessidade das populações rurais e marginais às cidades, cujo acesso à água costuma ser ainda mais negligenciado, bem como das minorias, em especial povos indígenas e mulheres periféricas (CG15, arts. 16 e 26). Tais dispositivos passam a ter especial relevância para a observação do direito em território nacional, já que a construção de hidroelétricas (LAUER, 2012, p. 5), o desenvolvimento de atividades mineradoras e outras atividades desenvolvimentistas impactam em primeira instância na disponibilidade de recursos hídricos para as populações indígena e rural. O direito humano à água recebe tratamento diferenciado, com exigências ainda mais abrangentes para a população indígena, tais como a garantia de água suficiente para manutenção de sua agricultura de subsistência (CG15, arts. 7 e 16(d); WEISS, 2013, p. 232-239).

Em defesa do Estado, pode ser invocado o caráter progressivo das obrigações decorrentes do PIDESC. Nos termos do art. 2 § 1 PIDESC, as obrigações ali previstas são programáticas e devem ser implementadas até o máximo dos recursos econômicos e técnicos disponíveis ao Estado. Isto quer

\footnotetext{
${ }^{11}$ Especificação quanto à qualidade da água consta em diversos documentos institucionais, mas os de maior aceitação estão previstos em ORGANIZAÇÃO MUNDIAL DA SAÚDE, 2011.
} 
dizer que as obrigações não são de resultado, mas de conduta, e podem ser implementadas passo a passo conforme as limitações de cada Estado (SEPÚLVEDA, 2003, p. 128). O retrocesso na garantia dos direitos é, no entanto, proibido, devendo o quadro geral permanecer, no mínimo, estável.

O caráter progressivo das obrigações estatais pode ser invocado quanto à obrigação de cumprir, como nos casos de necessidade de financiamento para aumento de redes de fornecimento de água, por exemplo. Entretanto, tal argumento perde peso principalmente quanto à obrigação do Estado de observar e proteger o direito existente perante terceiros, já que é mais difícil alegar a falta de capacidade técnica ou financeira em observar um direito instituído, como é o caso na outorga de licença de uso ou na autorização de poluição pela iniciativa privada.

Diante do exposto, não resta dúvida quanto ao reconhecimento, no atual sistema jurídico internacional, do direito humano à água de maneira vinculante, bem como quanto ao enquadramento normativo das obrigações estatais dele decorrentes. Os Estados estão obrigados a implementar medidas para observar, proteger e fazer cumprir o direito humano à água, nos termos expostos acima. No entanto, as possibilidades de reivindicação de direitos humanos em âmbito internacional ainda são extremamente limitadas, uma vez que o Protocolo Facultativo do PIDESC foi assinado e ratificado pela minoria dos Estados signatários. Necessário, por conseguinte, a análise da implementação do direito humano à água em âmbito regional, uma vez que ali se encontram cortes instituídas especialmente para a proteção de direitos fundamentais.

\section{PROTEÇÃO DO DIREITO HUMANO À ÁGUA NO SISTEMA INTERAMERICANO}

No âmbito regional interamericano, o direito humano à água também não está previsto expressamente na Convenção Americana de Direitos Humanos (Pacto de São José), mas pode ser inferido, de forma ampla, do direito à vida (art. 4), do direito à dignidade humana (art. 5), bem como do art. 11.1 do Protocolo Adicional ao Pacto de São José (Protocolo de São Salvador), que prevê a toda pessoa o direito a um meio ambiente equilibrado e aos serviços públicos básicos.

Quanto à ratificação expressa do direito à água na OEA, vale ressaltar a Resolução n. 2.349 da Assembleia Geral da OEA (05.06.2007), sobre “Água, Saúde e Direitos Humanos”, que reconhece, de forma abrangente, que a água é essencial para a vida e para a saúde de todos os seres humanos e que o acesso à água potável e saneamento básico é indispensável para uma vida com dignidade. Há quem considere o documento um retrocesso no reconhecimento da água como direito humano, pois ao longo das negociações foi excluída a definição expressa de acesso à água como direito humano, trazida no texto original apresentado pela delegação da Bolívia (HOHENWARTER, 2014, p. 91).

Revista da Faculdade de Direito - UFPR, Curitiba, vol. 61, n. 3, set./dez. 2016, p. 141 - 164 
Em 4 de junho de 2012, a Assembleia Geral da OEA aprovou a Carta Social das Américas, que serve de base legal para combater a pobreza e a injustiça social nos Estados-membros, na qual o livre e seguro acesso à água potável é classificado como um meio para combater a pobreza, mas não é em si reconhecido como direito humano. No dia seguinte, foi aprovada a sucinta Resolução sob o título “The Human Right to Safe Drinking Water and Sanitation” (AG/RES. 2760 (XLII-O/12)), reconhecendo o direito humano à água e fazendo referência à Resolução 64/292, da Assembleia Geral das Nações Unidas. É interessante notar que o curto documento ainda reafirma o direito soberano de cada Estado de estabelecer normas de uso e serviço de água em seu território.

Ainda assim, durante a negociação da AG/RES. 2760 (XLII-O/12), e como ressalva a esta, os EUA ressaltaram que sua constituição não prevê um direito à água e que este é, portanto, também não executável. O Canadá também fez uma ressalva quanto à aplicabilidade para recursos fronteiriços, ressaltando o aspecto progressivo das obrigações do Estado e negando a obrigação de ajuda ao desenvolvimento internacional.

A Corte Interamericana de Direitos Humanos (Corte IDH) tem, no entanto, contribuído de forma um pouco mais significativa para o fomento de um direito de acesso universal à água, já havendo feito referência ao CG15 em 2005, no julgamento do caso movido por Yakye Axa Indigenous Community contra o Paraguai (julgamento em 17 de junho de 2005, Série C, n. 125, § 167). Nele, a Corte IDH reconheceu que o direito de acesso à água potável está intrinsecamente ligado ao direito à saúde (art. 10 do Protocolo de São Salvador) e que sua realização impacta o exercício de todos os demais direitos.

Ainda, no mesmo julgado, água e saneamento foram expressamente mencionados como elementos integrantes do direito à moradia adequada (§ 164 da sentença). No caso em questão, os membros da comunidade indígena haviam sido retirados de seu território pelo governo paraguaio e, enquanto lutavam por seu direito de reaver suas terras, foram submetidos a condições precárias de subsistência (inclusive sem acesso à água e saneamento), enquanto também eram impedidos de acessar as fontes tradicionais de água em seu território. Por fim, o Estado do Paraguai foi condenado por infringir o direito à vida, previsto no art. 4(1) do Pacto de São José, em conjunto com o art. 1(1) do mesmo documento, que proíbe a discriminação na aplicação do Pacto.

Nos anos seguintes foram proferidas sentenças em mais dois julgamentos similares contra o Estado do Paraguai, nas quais foram feitas referências expressas ao CG15 por terem sido negados aos membros das comunidades indígenas o acesso à água em quantidade e qualidade suficientes, levando em alguns casos à morte, quais sejam: Sawhoyamaxa Indigenous Community contra Paraguai (julgamento em 29 de março de 2006, Série C n. 146 (§§ 148, 164 e 178)) e Xákmok Kásek Indigenous 
Community contra Paraguai (julgamento em 24 de agosto de 2010, Série C n. 214 (§§ 194 e 217)) $)^{12}$. Em ambos os casos, a Corte interpretou o direito humano de forma ampla e reiterou que ele gera tanto obrigações negativas (de não interferir no usufruto do direito) como positivas (pelas quais as condições mínimas para a vida devem ser garantidas por este direito) para o Estado (§ 151 da sentença).

No caso mais recente, movido por Xákmok Kásek Indigenous Community, a Corte IDH deu contornos mais claros às obrigações do Estado quanto ao fornecimento de água como condicionante do direito à vida (quantidade e qualidade mínima para sobrevivência), dedicando um subcapítulo da sentença ao tema. Ali são citados documentos legais, pesquisas e relatórios como base para fixação de um valor mínimo de 7,5 litros de água por pessoa/dia (§ 195 da sentença). Vale ressaltar que a fixação desse valor sofreu críticas por não incluir as necessidades de água para higiene (CHÁVARRO, 2014, p. 57). Por fim, a Corte IDH exigiu que o Paraguai preparasse estudos que pudessem garantir que o Estado estará fornecendo quantidade e qualidade mínimas de água para os membros da comunidade, conforme $\S 303$ da sentença.

A origem do problema dos três casos analisados acima esteve na remoção das comunidades indígenas de seu território ancestral, uma vez que a Região do Chaco havia sido vendida, na Bolsa de Valores de Londres, para investidores estrangeiros no final do século 19, sem que fosse dado conhecimento ou, muito menos, feita consulta às comunidades indígenas que a habitavam e dela subsistiam $^{13}$. Mesmo que as origens do conflito estejam relativamente distantes no tempo, nota-se também nesse caso o jogo desigual de forças, em que interesses econômicos se sobrepõem aos interesses imediatos de sobrevivência de indivíduos e comunidades.

Um segundo agrupamento de casos semelhantes que merece menção é o de sentenças proferidas em razão da falta de acesso à água e saneamento básico para detentos. O primeiro caso foi movido por López Álvarez contra Honduras (julgamento em 1 de fevereiro de 2006, Série C n. 141), no qual a Honduras foi condenada por violar o direito de integridade pessoal previsto no art. 5 (1), (2) e (4) do Pacto de São José ao não garantir o acesso à água durante a detenção de López Álvarez. Também foi feita referência expressa ao art. 3 da Convenção Europeia de Direitos Humanos, que proíbe a tortura.

Avanços com relação ao reconhecimento do direito humano à água são encontrados no caso

\footnotetext{
${ }^{12}$ Em ambos os casos as tribos indígenas estavam sendo retiradas de seu território ancestral e, durante sua luta, ficaram impedidas de permanecer em suas terras, instalando-se em locais nos quais não tinham acesso às fontes tradicionais de água às quais estavam acostumados em suas terras, e tampouco à infraestrutura de água e saneamento adequada à dignidade humana.

${ }^{13} \S 73(1)$ do julgamento do caso movido por Sawhoyamaxa Indigenous Community.
} 
movido por Vélez Loor contra Panamá (julgamento em 23 novembro 2010, Série C n. 128), no qual a falta de água potável e de saneamento básico dentro de um presídio foi condenada como falta grave do Estado quanto à proteção do direito da dignidade humana prevista no art. 5 (1 e 2) do Pacto de São José (§§ 215 e seguintes e § 227 da sentença). Aqui o CG 15 e a Resolução 64/292 da Assembleia Geral das Nações Unidas também foram expressamente citados, em conjunto com a Resolução 2.349 da Assembleia Geral da OEA (XXXVII-O/07), para alicercear a obrigação do Estado de tomar as medidas necessárias para garantir aos detentos acesso à água potável e saneamento (§ 215 da sentença).

Vale aqui ressaltar, ainda, o polêmico caso que envolveu a atuação da Comissão Interamericana de Direitos Humanos (CIDH) (2011, p. 1) e o Estado brasileiro, em 2011, no qual foi proferida por aquele órgão a Medida Cautelar n. 382/10, solicitando, entre outras medidas, que o Estado "adote medidas para proteger a vida, a saúde e integridade pessoal dos membros das comunidades indígenas” afetadas pela construção da usina hidroelétrica de Belo Monte, na Bacia do Rio Xingu.

O caso demonstra a tentativa da CIDH de ampliar o seu nível de atuação para incluir demandas da "nova ordem global”, entre as quais está o desenvolvimento sustentável e o respeito a direitos difusos ou de minorias. O Brasil, no entanto, pautando-se em sua soberania, recusou-se a suspender as obras da usina, deslegitimando a tentativa da CIDH, que veio a revogar a medida cautelar. O caso demonstra que o sistema interamericano ainda não foi capaz de atender às demandas da nova ordem global e, assim, “[...] as solicitações de minorias que se veem reprimidas pelos seus governos e cujos direitos humanos estejam ameaçados” (SICILIANO, 2011, p. 5). No final de 2015 foi dado andamento ao processo apresentado pela sociedade civil à CIDH - o desenvolvimento se dará ao longo do ano de 2016. O Brasil vem lentamente ampliando seu preparo executivo para responder e implementar as demandas do CIDH (BERNARDES, 2011).

Conclui-se, preliminarmente, que, apesar dos instrumentos de caráter político normativo mencionados acima, bem como da ainda evasiva tentativa de prevenir a infração de direitos humanos, a Corte IDH já reconhece o direito humano à água, nos termos do CG15, desde 2005, e vem aprofundando a análise quanto às obrigações estatais decorrentes, conforme visto no julgamento de 2010. Assim, a Corte IDH contribui de forma significativa para dar os contornos jurídicos para os elementos que possibilitem uma aplicação efetiva do direito em tela, bem como uma interpretação uniforme necessária para a constituição de direito costumeiro vinculante.

A fim de verificar a existência dos elementos que permitem o surgimento de direito costumeiro (prática estatal e opinio juris), bem como para verificar o alcance da interpretação dada 
ao direito humano à água por outros tribunais, e considerando que a Corte IDH e a Corte EDH tem objetivos análogos e colaboram entre si para unificação da jurisprudência, cumpre, ainda, analisar o reconhecimento e a implementação do direito humano à água também em âmbito europeu.

\section{PROTEÇÃO DO DIREITO HUMANO À ÁGUA NO SISTEMA EUROPEU}

A Convenção Europeia de Direitos Humanos (CEDH) entrou em vigor em 1953 com força vinculante para seus signatários, e tem por objetivo criar um sistema protetivo e mecanismos de controle, em nível regional, para os direitos humanos previstos na DUDH.

A CEDH também não prevê expressamente um direito humano à água. Mas este é dedutível (i) do direito à vida previsto no art. 2 (1), (ii) do direito a ter sua vida privada e familiar respeitada previsto no art. 8 da CEDH e (iii) da proibição de tortura e tratamento desumano previsto no art. 3 da CEDH, se considerados em conjunto com outros diplomas legais - em especial, a Carta Europeia de Recursos Hídricos, que é parte integrante da Recomendação aos Estados-membros emitida pelo Comitê de Ministros do Conselho Europeu em 17 de janeiro de $2001^{14}$. A Carta Europeia de Recursos Hídricos reconhece expressamente, em seu § 5, o direito à água, em quantidade e qualidade suficientes, para as necessidades básicas humanas, bem como a prioridade do uso público, racional e equitativo do recurso, com base no art. 25 da DUDH e no art. 11 do PIDESC (conforme veio a ser concretizado posteriormente pelo CG15 em nível global) (LASKOWSKI, 2010, p. 199-202).

A Carta Europeia de Recursos Hídricos abrange ainda os aspectos de sustentabilidade, exigindo o manejo que permita o cumprimento do direito para as gerações presentes e futuras, bem como exigindo um manejo integrado do recurso, baseado na Declaração do Rio de Janeiro sobre o Meio Ambiente de 1992 (Carta Europeia de Recursos Hídricos, art. 1; LASKOWSKI, 2010, p. 200). As políticas públicas e a legislação referentes à água devem ser baseadas, conforme o art. 8 da Carta Europeia de Recursos Hídricos, no princípio da precaução, no princípio da prevenção e no princípio do poluidor-pagador. Tal documento enquadra-se como soft law e vincula os Estados-membros, principalmente em âmbito político.

Tal entendimento também é sustentado pela Corte EDH. Em 10 de fevereiro de 2011 foi julgado o caso de Dubetska e outros contra a Ucrânia (n. 30.499/03), no qual, em razão de atividades mineradoras e industriais, ocorreram danos substanciais por poluição ao meio ambiente, alcançando inclusive o lençol freático, causando assim danos à saúde das famílias que viviam próximas aos

\footnotetext{
${ }^{14}$ Tal documento foi ratificado pela Assembleia Parlamentar do Conselho Europeu em 25 de junho de 2004, o qual tem se manifestado, desde então, sempre de forma favorável quanto ao reconhecimento do direito humano em âmbito internacional.
}

Revista da Faculdade de Direito - UFPR, Curitiba, vol. 61, n. 3, set./dez. 2016, p. 141 - 164 
empreendimentos e que sofreram com irregularidades na quantidade e qualidade da água potável fornecida.

A Ucrânia falhou na solução do problema ao longo de doze anos, nos quais os requerentes reclamaram por seus direitos, pelas vias nacionais. Apesar de o governo ter reconhecido, em diversas ocasiões, a gravidade da poluição e a necessidade da realocação das famílias que viviam nas áreas afetadas pela degradação e mesmo a necessidade de interrupção das atividades poluidoras, não foram tomadas medidas nesse sentido (§§ 118 e 152 da sentença). Por fim, o Estado foi condenado por descumprir suas obrigações, nos termos do art. 8 da CEDH (direito a ter sua vida privada e familiar respeitada).

Foram ainda julgados dois outros casos nos quais os Estados foram condenados pela Corte EDH com base no art. 8 da CEDH por não controlarem ou tomarem as medidas necessárias para mitigar os efeitos poluentes de atividades industriais e mineradoras sobre os recursos hídricos que abasteciam os indivíduos da região - quais sejam, o caso Taskin e outros contra Turquia, n. 46.117/99, de 10 de novembro de 2004, e o caso de Tatar contra Romênia, n. 67.021/01, de 27 de janeiro de 2009.

Adicionalmente, foram julgados diversos casos relacionados com as condições mínimas necessárias em centros de detenção, nos quais reiteradamente o acesso à água e saneamento básico foi considerado como essencial para a dignidade humana. Em todos os casos, a situação foi considerada cruel e desumana e os Estados foram condenados, nos termos do art. 3 da CEDH (proibição de tortura) $)^{15}$.

Entre os diplomas legais que regem a matéria em âmbito europeu, existe ainda a Carta Social Europeia $(\mathrm{CSE})^{16}$, que é o equivalente regional ao PIDESC. Nela também não está previsto expressamente um direito à água. Porém, o órgão de controle da CSE, o Comitê Europeu de Direitos Sociais (Comitê EDS), já se manifestou em diversas ocasiões sobre o tema.

A existência de um sistema de fornecimento de água potável e saneamento básico foi considerada como condicionante para a adequabilidade de moradias ou residências populares, e a sua falta foi tida como violação do direito à moradia (art. 31 CSE), do direito à saúde (art. 11 CSE) e do

\footnotetext{
${ }^{15}$ Fedotov contra Rússia, App n. 5140/02, julgamento em 24 de outubro de 2005, § 66 e sg.; Babushkin contra Rússia, Ap. n. 67253/01, julgamento em 18 de outubro de 2007, § 19 e sg., § 47 e sg.; Generalov contra Rússia, App n. 24325/03, julgamento em 09 de julho de 2009, § 110 e sg.; Iacov Stanciu contra Romênia, Ap. n. 35972/05, julgamento em 24 de julho de 2012, § 175 e 179, e Petriks contra Letônia, Ap. n. 19619/03, julgamento em 4 de dezembro de 2012, § 26 e sg., entre outros. Para uma lista detalhada, veja CHÁVARRO, 2014.

${ }^{16} \mathrm{O}$ documento original é de 1961, tendo entrado em vigor em 1965. Uma nova versão foi promulgada em 1996, à qual é feita referência neste artigo sobre a abreviação CSE.
} 
direito familiar de proteção social, legal e econômica (art. 16 CSE) - em alguns casos, em conjunto com a proibição de discriminação (art. E CSE) ${ }^{17}$. Vale destacar o caso movido pela International Federation of Human Rights contra a Grécia, cujo julgamento foi proferido em 23 de janeiro de 2008, Ap. n. 72/2011, no qual a Grécia foi condenada por violação do direito à saúde (previsto no art. 11 da CSE em sua redação original de 1961), diante de sua demora em reconhecer os altos níveis de poluição do rio Asopos, causada por resíduos industriais, bem como por não tomar as medidas mitigatórias para minimizar o dano à saúde da população.

Além disso, também foi condenada por não informar a população sobre os riscos no consumo da água e, em alguns casos, por ter inclusive se recusado a fornecer informações ( $\S \S 130$ e 153 da sentença) (HOHENWARTER, 2014, p. 87).

Diante do exposto, é possível verificar que o direito humano à água encontra respaldo no sistema europeu de direitos humanos, em especial como um direito decorrente do direito à vida (art. 2(1) $\mathrm{CEDH}$ ), da proibição de tortura (art. $3 \mathrm{CEDH)}$ e do direito a ter sua vida privada e familiar respeitada (art. $8 \mathrm{CEDH})$, bem como do direito à moradia (art. $31 \mathrm{CSE}$ ), à saúde (art. $11 \mathrm{CSE}$ ) e do direito familiar de proteção social, legal e econômica (art. 16 CSE). São especificadas, ainda, as medidas que devem ser adotadas pelos Estados na Carta Europeia de Recursos Hídricos. A fim de verificar a uniformidade no tratamento dado pelas cortes regionais ao direito à água será realizada a seguir uma comparação entre o sistema europeu e o sistema interamericano de proteção de direitos humanos ora expostos.

\section{COMPARAÇÃO DOS SISTEMAS INTERAMERICANO E EUROPEU NO TOCANTE À PROTEÇÃO DO DIREITO HUAMANO À ÁGUA}

Quanto ao aspecto regulatório, ambos os sistemas, interamericano e europeu, possuem apenas instrumentos de soft law. O sistema europeu é mais robusto e oferece recomendações mais detalhadas para os Estados, em especial por meio da Carta Europeia de Recursos Hídricos, que, mesmo tendo sido elaborada antes do CG15, inclui importantes aspectos de garantia do direito, não somente para as gerações presentes, mas também para as futuras, ao exigir a observância de sustentabilidade, no uso do recurso, e de demais princípios de direito ambiental.

Já a OEA restringe-se a reconhecer os aspectos básicos de garantia de água para

\footnotetext{
${ }^{17}$ Comitê EDS: International Movement ATD Fourth World contra França, n. 33/2006, julgamento em 5 de dezembro de 2007; European Federation of National Organisations working with the Homeless contra França, n. 39/2006, julgamento em 5 de dezembro de 2007; European Roma Rights Centre contra França, n. 51/2008, julgamento em 19 de outubro de 2009, entre outros. Para uma lista detalhada de casos veja CHÁVARRO, 2014.
} 
sobrevivência, fazendo apenas rápida referência ao direito de gerações futuras. E, assim mesmo, reconhece o direito à água de forma evasiva e com ressalvas por dois de seus agentes mais influentes politicamente: os Estados Unidos e o Canadá.

Ainda, a inclusão mais predominante de aspectos ambientais no sistema europeu também se reflete na jurisprudência, que, conforme os casos listados acima, lida com casos de poluição do recurso.

Mais interessante é o tratamento jurisprudencial conferido pelas cortes ao direito humano à água. O sistema europeu fundamenta o direito à água nos artigos 2(1), 3 e 8 da CEDH, correspondentes ao direito à vida, à proibição de tortura e ao direito a ter sua vida privada e familiar respeitada. A Corte IDH também recepciona o direito à água como condicionante dos demais direitos humanos, em especial do direito à vida, previsto no art. 4, e do direito à integridade pessoal e tratamento humano previsto no art. 5 do Pacto de San José.

Além disso, a Corte IDH faz referências expressas ao CG15 e reconhece, portanto, o direito à água como decorrente do rol exemplificativo do art. 11 e do art. 12 do PIDESC, e se aprofunda quanto ao conteúdo das obrigações do Estado decorrentes de um direito à água, colaborando de forma significativa para a definição de uma linha interpretativa.

Por seu turno, ambas as cortes reconheceram obrigações positivas do Estado para garantir o acesso à água, tal como demonstrado nos casos movidos perante a Corte EDH, e expressamente mencionados no caso movido pela Xákmok Kásek Indigenous Community perante a Corte IDH.

Destacam-se os casos semelhantes, em ambas as Cortes, referentes ao acesso à água e ao saneamento básico em centros de detenção. As limitações de acesso à água e ao saneamento básico impostas pelos Estados foram consideradas como infrações desumanas por ambas as Cortes. A Corte IDH baseou a obrigação do Estado de fornecer água potável e saneamento básico no art. 5 do Pacto de São José e na jurisprudência da Corte EDH, enquanto a Corte EDH fundamentou tal obrigação na proibição à tortura, art. 3 da CEDH.

O sistema interamericano pode beneficiar-se da experiência do sistema europeu quanto ao julgamento de casos de poluição industrial, em especial os casos julgados com base no art. 8 CEDH. O julgamento também é relevante em vista dos casos similares ocorridos no Brasil, como, por exemplo, o rompimento da barragem de rejeitos de mineração controlada pela mineradora Samarco Mineração S.A., localizada no município de Mariana, Minas Gerais, causando danos de proporções devastadoras na Bacia do rio Doce.

Por sua vez, o sistema europeu pode, a exemplo da Corte IDH, incluir as especificações fornecidas pelo CG15 para melhor determinar as obrigações do Estado pela garantia do direito de 
acesso à água e assim corroborar para formar uma linha interpretativa mais uniforme.

Verifica-se, portanto, que ambos os sistemas confirmam a existência do direito à água e encontram bases legais para sua execução, desempenhando, destarte, papel importante no avanço da definição dos contornos interpretativos para o direito subjetivo, bem como na sua aceitação, implementação e reconhecimento em níveis global, regional e nacional.

\section{CONCLUSÃO}

O Direito Internacional deu um importante passo para o reconhecimento e consolidação do direito humano à água ao definir seu conteúdo normativo no CG15, e caminha em direção à consolidação de um direito costumeiro, vinculante para os Estados.

Por ora, o tema tem caráter de soft law e constitui forte compromisso político dos Estados para garantir as necessidades básicas humanas quanto à água e saneamento para gerações presentes e futuras. Os sistemas regionais acompanham a tendência de fortalecimento do direito em âmbito internacional e acrescentam elementos para a formação de uma linha interpretativa. Não obstante, a grande maioria dos Estados está vinculada a garantir o direito à água por acordos internacionais, seja pelo PIDESC, CEDAW, CPC ou CPD.

Apesar de as decisões dos tribunais internacionais serem vinculantes apenas entre as partes, desempenham um papel importante em definir os fundamentos, e corroboram para o reconhecimento legal de um direito à água (HOHENWARTER, 2014, p. 92). Mesmo que ainda em número modesto, as decisões de ambas as Cortes inegavelmente incluem o acesso à água potável como condicionante da realização de outros direitos humanos.

Os sistemas podem se beneficiar mutuamente das interpretações e compreensões desenvolvidas em diversos julgados, já que ambas as Cortes apresentam casos bem fundamentados cujas situações potencialmente se repetirão em ambas as regiões. O Sistema Interamericano pode se beneficiar dos casos que foram utilizados no Sistema Europeu para condenar os Estados por poluição dos recursos, enquanto a Corte EDH pode se embasar nos julgamentos proferidos em casos de violação do direito à vida ancorado expressamente no direito à água, conforme definido no CG15.

Quanto à eficácia do direito como ferramenta para proteção tanto de interesses individuais imediatos quanto interesses difusos mediatos, é interessante notar que, em casos apresentados perante ambas as Cortes, verifica-se a necessidade de estabelecer mecanismos para o reequilíbrio do jogo de forças entre os interesses econômicos (representados pelo Estado soberano e/ou pela iniciativa privada) e os interesses da população, diretamente atingida pelas consequências negativas do 
desenvolvimento de tais atividades e sem a devida compensação ou até mesmo sem a garantia de direitos fundamentais para sobrevivência, saúde, dignidade humana e não discriminação.

Nos casos das comunidades indígenas julgados pela Corte IDH é possível verificar a tutela protetiva concedida no nível comunitário imediato, enquanto que no caso da poluição do rio Asopos, julgado pelo Comitê EDH, bem como nos casos julgados pela Corte EDH com base no art. 8 CEDH, é possível verificar a proteção em nível coletivo difuso. Constata-se, portanto, que, enquanto aplicado, um direito à água, em conjunto com os demais direitos humanos, tem eficácia na mitigação de deficiências na governança internacional do mundo globalizado. Assim, a efetiva condenação de Estados pode gerar incentivos para que eles tomem medidas preventivas e atuem de forma mais eficiente na administração dos interesses econômicos que estão em oposição aos interesses de sobrevivência de grupos com menos força política.

Vale ressaltar que diversos casos polêmicos ocorridos em território brasileiro se assemelham a casos analisados neste artigo, os quais resultaram em condenação do Estado por descumprimento de direitos humanos e das obrigações estatais decorrentes. Principais exemplos são os casos julgados pela Corte IDH sobre a remoção de povos indígenas de suas terras e a sua realocação em locais inapropriados, em comparação à situação de remoção e ausência de consulta à população indígena e ribeirinha, denunciada pela sociedade civil, na construção da hidroelétrica de Belo Monte, na Bacia do Xingu (GAMA, 2016; PROGRAMA XINGU, 2015; WWF 2011).

A água é elemento substancial dos desafios organizacionais internacionais presentes e futuros, pois, apesar de ser também um elemento essencial à continuação do processo produtivo, que hoje se dá em nível global, não pode ser tutelada seguindo apenas as lógicas de mercado, o que implicaria administrar sua escassez por intermédio da lei da oferta e da procura, a qual institui o preço de mercado.

A questão da qualificação jurídica da água em sua dimensão de direito subjetivo representa, assim, na qualidade de elemento que liga direitos humanos e interesses econômicos, uma oportunidade, se não uma obrigação, de se balancearem as necessidades econômicas com as humanas imediatas e ambientais.

\section{REFERÊNCIAS}

\section{DOUTRINA E ATOS NORMATIVOS}

AGÊNCIA NACIONAL DE ÁGUAS (ANA) / INSTITUTO BRASILEIRO DE MINERAÇÃO (IBRAM). A Gestão Dos Recursos Hídricos e a Mineração. Brasília: ANA/IBRAM, 2006. Disponível em: <https://goo.gl/arirJ8>. Acesso em: 15 fev. 2016. 
AGÊNCIA NACIONAL DE ÁGUAS (ANA). Relatório de Conjuntura dos Recursos Hídricos no Brasil - 2013. Brasília: ANA, 2013. Disponível em: <https://goo.gl/mcNt9G>. Acesso em: 10 fev. 2016.

ALEXY, Robert. Teoria dos Direitos Fundamentais. Trad. Virgílio Afonso da Silva. São Paulo: Malheiros, 2008.

ASSEMBLEIA GERAL DAS NAÇÕES UNIDAS. Achievements of the International Dirnkina [sic] Water Supply and Sanitation Decade, Report of the Secretary General. UN Doc A/45/327, de 13 jul. 1990.

BERNARDES, Marcia Nina. Sistema Interamericano de Direitos Humanos como esfera pública transnacional: aspectos jurídicos e políticos da implementação de decisões internacionais. Conectas Direitos Humanos, v. 8, n. 15, jan/2011. Disponível em: <https:/goo.gl/XwKLSu>. Acesso em: 1 fev. 2016.

BLUEMEL, Erik. The Implications of Formulating a Human Right to Water. Ecology L.Q., v. 31, n. 4, 2004. Disponível em: <https://goo.gl/G0dK0V>. Acesso em: 20 jan. 2016.

CHÁVARRO, Jimena Murillo. The Right to Water in the Case-Law of the Inter-American Court of Human Rights. ACDI, vol. 7, Bogotá, 2014, p. 39-68.

COMISSÃO INTERAMERICANA DE DIREITOS HUMANOS (CIDH). Medida Cautelar 382/10 - Comunidades Indígenas da Bacia do Rio Xingu, Pará, Brasil, 2011. Disponível em: $<$ https://goo.gl/BA2VkE>. Acesso em: 17 mar. 2016.

CONVENTION ON THE ELIMINATION OF ALL FORMS OF DISCRIMINATION AGAINST WOMEN (CEDAW). Texto da Convenção. Nova Iorque: CEDAW, 1979.

CONVENTION ON THE RIGHTS OF PERSONS WITH DISABILITIES (CRPD). Texto da Convenção. Nova Iorque: CRPD, 2006.

CONVENTION ON THE RIGHTS OF THE CHILD (CRC). Texto da Convenção. Nova Iorque: CRC, 1989.

COUNCIL OF EUROPE/COMMITTEE OF MINISTERS. Recommendation Rec(2001)14 of the Committee of Ministers to member states on the European Charter on Water Resources, 17 de outubro de 2001. Disponível em: <https://goo.gl/fqE057>. Acesso em: 26 jul. 2016.

DUPUY, Pierre-Marie. Formation of Costumary International Laws and General Principles. In: The Oxford Handbook of International Environmental Law. Oxford: Oxford University Press, 2007, p. 450-463.

FARIA, Ricardo Coelho de; FARIA, Simone Alves de; MOREIRA, Tito Belchior S. A privatização no setor de saneamento tem melhorado a performance do serviço? Planejamento e políticas públicas, 28, jun./dez. 2005. Disponível em <https://goo.gl/MBR45>. Acesso em: 20 jan. 2016.

GAMA, Aliny. Brasil vai responder na OEA por violações de direitos humanos em Belo Monte. Uol Notícias, Maceió, 13/01/2016. Disponível em: <https://goo.gl/0HakNL>. Acesso em: 20 mar. 2016. 
GANDRA, Alana. Estudo confirma impactos da mineração no país. EBC - Agência Brasil, Rio de Janeiro, 22/12/2014. Disponível em: <https://goo.gl/j7ebru>. Acesso em: 1 fev. 2016.

HELLER, Léo; SADI, Waleed. Right to sanitation, a distinct human right - Over 2.5 billion people lack access to sanitation. Genebra: UNHR, 2015. Disponível em: <https://goo.gl/x8v9fC>. Acesso em: 2 fev. 2016.

HOHENWARTER, Bettina. Das Recht auf Wasser, Die menschenrechtliche Verantwortung von Staaten und Unternehmen. Viena: Neuer Wissenschaftlicher Verlag, 2014.

INSTITUTE FOR AGRICULTURAL AND TRADE POLICY (IATP). IMF and World Bank Push Water Privatization and Full Cost Recovery on Poor Countries. Minneapolis: IATP, 2002. Disponível em: <https://goo.gl/HRFmZS>. Acesso em: 25 jan. 2016.

KUNIG, Philip. Das Völkerrecht auf dem Weg zu einem Recht der Weltbevölkerung? In: MURAKAMI, Junichi; MARUTSCHKE, Hans-Peter; RIESENHUBER, Karl. Globalisierung und Recht. Berlim: Walter de Gruyter, 2007. p. 187-199.

LASKOWKSI, Silke Ruth. Das Menschenrecht auf Wasser. Kassel: Tübingen Mohr Siebeck, 2010.

LAUER, Kristina. Das Konfliktverhältnis Wasserkraft contra Umweltschutz. Berlim: Erich Schmidt Verlag, 2012.

LEFLAIVE, X. et al. “Water”. In: OECD. OECD Environmental Outlook to 2050: The Consequences of Inaction. Paris: OECD Publishing, 2012. Disponível em: <https://goo.gl/ncY1jl>. Acesso em: 15 mar. 2016.

LEWIS, Bridget, Balancing human rights in climate policies. In: QUIRICO, Ottavio; BOUMGHAR, Mouloud (Ed.). Climate Change and Human Rights. An International and Comparative Law Perspective. Nova Iorque: Routledge, 2016.

LOHSE, Oliver. Das Recht auf Wasser als Verpflichtung für Staaten und nichtsaatliche Akteure. Art. 11 Abs. 1, Art. 12 Internationaler Pakt über wirtschaftliche, soziale und kulturelle Rechte. Hamburgo: Verlag Dr. Kovac, 2005.

MARTIN, Paul et al. The Search For Environmental Justice. Londres: Edward Elgar Publishing, 2015.

MAZZUOLI, Valerio de Oliveira. O Sistema Regional Europeu de Proteção dos Direitos Humanos. In: Cadernos da Escola de Direito e Relações Internacionais - Unibrasil, Curitiba, 13:32-58 vol. 1, 2010. Disponível em: <https://goo.gl/wlNBrm>. Acesso em: 15 mar. 2016.

NAÇÕES UNIDAS. Report of the United Nations Water Conference, Mar de Plata, 14-25 March 1977. United Nations Publications, Sales No.E.77.II.A.12. Parte I, Cap. I. Disponível em: $<$ https://goo.gl/sjHxfT>. Acesso em: 14 jan. 2016.

NICKSON, Andrew; VARGAS, Claudia. The Limitations of Water Regulation: The Failure of the Cochabamba Concession in Bolivia. In: Bulletin of Latin Am. Res., v. 21, n. 1, p. 99-120, 2002. 
ORGANIZAÇÃO MUNDIAL DA SAÚDE (OMS). Guidelines for drinking-water quality. 4. ed. Genebra: OMS, 2011. Disponível em: <https://goo.gl/LQEVQL>. Acesso em: 25 jul. 2016.

PROGRAMA XINGU - INSTITUTO SOCIOAMBIENTAL. Dossiê Belo Monte: Não há condições para a Licença de Operação. VILLAS-BÔAS, André et al. (Org.). São Paulo: Programa Xingu Instituto Socioambiental, junho de 2015. Disponível em: <https://goo.gl/JXEFCb>. Acesso em: 28 mar. 2016.

RUDOLF, Beate. Menschenrecht Wasser - Herleitung, Inhalt, Bedeutung und Probleme. In: Menschenrecht Wasser? Frankfurt: Peter Lang GmbH, 2007.

SEPÚLVEDA, M. Magdalena. The Nature of the Obligations under the International Covenant on Economic, Social and Cultural Rights. Utrecht: Intersentia, 2003.

SICILIANO, André. O caso de Belo Monte na Comissão Interamericana de Direitos Humanos: análise em dois níveis. III Simpósio de Pós-Graduação em Relações Internacionais do Programa “San Tiago Dantas” (UNESP, UNICAMP e PUC/SP) - 8 a 11 de novembro de 2011. Disponível em: <https://goo.gl/hLq7Mj>. Acesso em: 17 mar. 2016.

UNITED NATIONS DEVELOPMENT PROGRAMME (UNDP). Human Development Report 2006. Beyond Scarcity: Power, Poverty and the Global Water Crisis. Nova Iorque: UNDP, 2006. Disponível em: <https://goo.gl/Hmq4kP>. Acesso em: 15 mar. 2016.

VIEIRA JR., Dicesar Beches. Teoria dos direitos fundamentais: evolução histórico-positiva, regras e princípios. Revista da Faculdade de Direito-RFD-UERJ, Rio de Janeiro, 2015, p. 93-94.

WEISS, Edith Brown. International Law for a Water-Scarce World. The Hague Academy of international law monographs, vol. 7. Leiden: Martinus Nijhoff Publishers, 2013.

WINKLER, Inga T. The Human Right to Water: Significance, Legal Status and Implications for Water Allocation. Oregon: Hart Publishing, 2012.

WORLD WIDE FUND FOR NATURE - BRASIL (WWF-BRASIL). Serious risks expected to the Belo Monte hydroelectric dam project due to climate change impacts in the Amazon. Brasília: WWFBRASIL, 2011. Disponível em: <https://goo.gl/oCqKgd>. Acesso em: 25 mar. 2016.

\section{JURISPRUDÊNCIA}

COMITE EUROPEU DE DIREITOS SOCIAIS. European Federation of National Organisations working with the Homeless contra França, n. 39/2006, julgamento em 5 de dezembro de 2007.

2009.

. European Roma Rights Centre contra França, n. 51/2008, julgamento em 19 de outubro de . International Federation of Human Rights contra Grécia, Denúncia n. 72/2011, 23 de janeiro de 2008.

. International Movement ATD Fourth World contra França, n. 33/2006, julgamento em 5 de

Revista da Faculdade de Direito - UFPR, Curitiba, vol. 61, n. 3, set./dez. 2016, p. 141 - 164 
dezembro de 2007.

CORTE EUROPEIA DE DIREITOS HUMANOS. Babushkin contra Rússia, n. 67253/01, julgamento em 18 de outubro de 2007.

. Dubetska e outros v. Ucrânia, App n. 30499/03, 10 de fevereiro de 2011.

. Fedotov contra Rússia, n. 5140/02, julgamento em 24 de outubro de 2005.

. Generalov contra Rússia, n. 24325/03, julgamento em 9 de julho de 2009.

. Petriks contra Letônia, n. 19619/03, julgamento em 4 de dezembro de 2012.

. Taskin e outros contra Turquia, n. 46117/99, julgamento em 10 de novembro de 2004.

. Tatar contra Romênia, n. 67021/01, julgamento em 27 de janeiro de 2009.

CORTE INTERAMERICANA DE DIREITOS HUMANOS. López Álvarez contra Honduras, julgamento em 1 de fevereiro de 2006, Serie C, n. 141.

Sawhoyamaxa Indigenous Community contra Paraguai, julgamento em 29 de março de 2006, Série C n. 146.

. Vélez Loor contra Panama, julgamento em 23 de novembro de 2010.

. Xákmok Kásek Indigenous Community contra Paraguai, julgamento em 24 de agosto de 2010, Serie C, n. 214.

Yakye Axa Indigenous Community contra Paraguai, julgamento em 17 de junho de 2005, Serie C, n. 125.

\title{
WATER AS A HUMAN RIGHT: COMPARATIVE STUDY OF ITS PROTECTION IN THE INTER-AMERICAN AND EUROPEAN JURISPRUDENTIAL SPHERES
}

\begin{abstract}
The management of water resources - so that priority is given to its use to fulfill the human basic biological needs for present and future generations - is a topic of international and national concern, having just lately increased in importance in Brazil. In response to the concerns of the international community, a human right to water has gained force in international politics in the last decades and has been gradually incorporated into the legal arena. This article analyses the stand of the right to water in international law and, considering especially the available case law, builds up a comparative study of its implementation in the Inter-American and European systems for the protection of human rights, with the aim to identify its applicability, effectiveness, and the corresponding State's obligations. It concludes that the recognition of the human right to water can work as an important instrument to protect direct individual rights, as well as indirect collective rights, in face of the current political and economic global order.
\end{abstract}


ÁGUA COMO DIREITO HUMANO: ESTUDO COMPARADO DE SUA PROTEÇÃO NAS ESFERAS [...]

KEYWORDS

Human rights. Water. Regional systems for the protection of human rights. Comparative study. State's obligation.

Recebido: 29 de março de 2016

Aprovado: 12 de setembro de 2016

Revista da Faculdade de Direito - UFPR, Curitiba, vol. 61, n. 3, set./dez. 2016, p. 141 - 164 